\title{
Primary afferent depolarization: direct evidence in the trigeminal system
}

\author{
H. H. YU* AND J. K. AVERY
}

Neurophysiology Laboratory, Department of Oral Biology, Dental Research Institute, The University of Michigan, Ann Arbor, Mich. 48104 (U.S.A.)

(Accepted April 10th, 1974)

Sensory inputs carried by the peripheral nerve fibers can be regulated at the central terminals of the fibers. Both intracellular ${ }^{1,13,17}$ and extracellular ${ }^{12,15,21,25}$ recordings at the levels of the spinal cord and dorsal column nuclei have provided evidence for modification of afferent impulses. However, in the trigeminal system only extracellular recordings, which provide indirect evidence of excitability changes of primary afferents, are available $2,7,10,11,22,23,26$. Although the possible cause of the dorsal root potentials has been reported, the nature of the pathway involved is not well known. In this study, we undertook to record the primary afferent depolarization (PAD) intracellularly from central preterminals. We have also performed experiments to clarify the role of inhibitory neurons influencing the PAD and to determine the possible role of gamma-aminobutyric acid (GABA) as a transmitter substance ${ }^{6}$ in the trigeminal afferent systems.

Cats anesthetized with Nembutal $(35 \mathrm{mg} / \mathrm{kg})$ or chloralose $(70 \mathrm{mg} / \mathrm{kg})$ were used in this study. Animals were artificially ventilated following injections of gallamine (Flaxedil) to eliminate muscular twitching. The spinal tract or nuclei of the trigeminal nerves $(\mathrm{Tn})$ were approached vertically from the dorsal surface of the brain stem by the stereotaxic method. Central preterminals of the Tn were activated by stimulation of the ipsilateral peripheral branches of the Tn after the nerve emerged from the infraorbital foramen or when it was in the exposed inferior alveolar canal by using a pair of silver electrodes. Stimuli were brief current pulses of $0.05-0.1$ msec duration. Glass microelectrodes were used to record field potential $(2 \mathrm{M} \mathrm{NaCl}$, DC resistance 2-5 $\mathrm{M} \Omega$ ) and intracellular potential (3 $\mathrm{M} \mathrm{KCl}, 7-12 \mathrm{M} \Omega$ ) changes. The amplification and oscilloscope display of the response signals, as well as the filming, was conventional. At the end of each experiment the recording and stimulation sites were identified histologically.

Fig. 1A-D illustrates the primary afferent depolarization (PAD) and trigeminal dorsal root reflex (TDRR) recorded inside the preterminal fibers in the rostral part of the spinal nucleus or spinal tract. Fig. 1E-F shows the field potentials recorded adjacent to the fibers. The extracellular potentials usually consisted of a small positive

* Present address: Tufts University School of Dental Medicine, 1 Kneeland Street, Boston, Mass. 02111, U.S.A. 
A
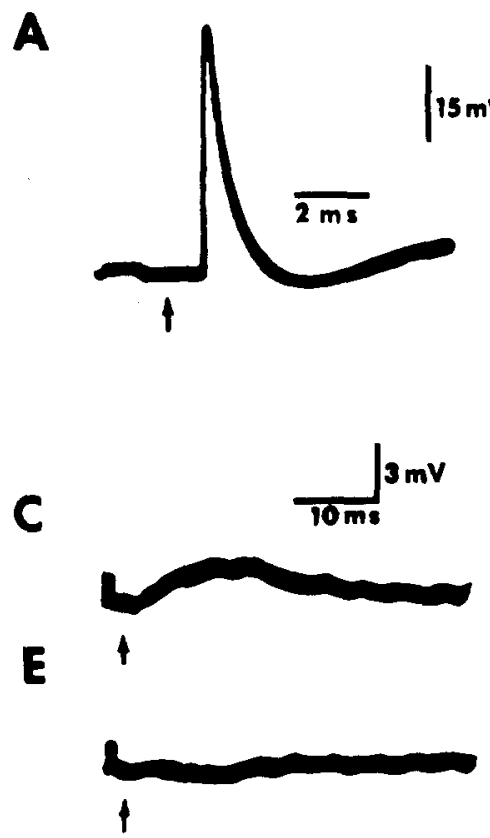

B

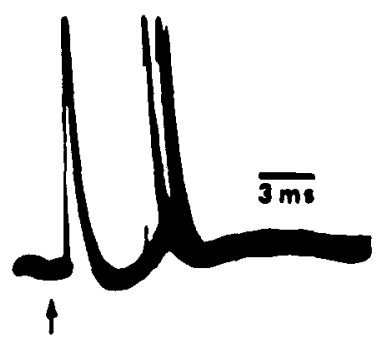

D

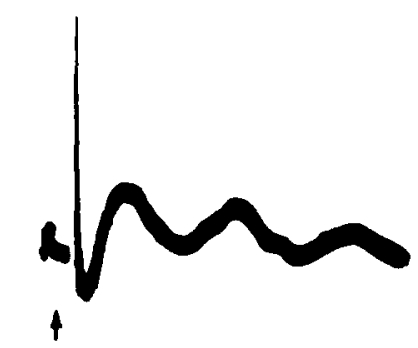

$\boldsymbol{F}$

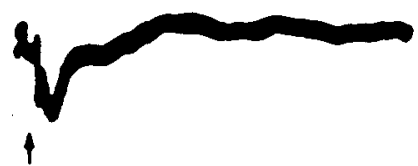

Fig. 1. Intrafiber recording from the central preterminal of an inferior alveolar nerve fiber. A: identification of the fiber. The fiber action potential is followed by a primary afferent depolarization. Stimulus intensity was near the threshold of the impaled fiber. B: TDRR on top of PAD resulting from single pulse stimulation. The stimulus intensity was greater than in A. Three sweeps were superimposed. C: PAD without spike. The stimulus intensity was subthreshold for the impaled nerve fiber. D: prolonged PAD preceded by a spike. $\mathrm{E}$ and $\mathrm{F}$ : extracellular recordings. The recording site was just adjacent to the unit in A-D. The stimulus intensities are the same as those of $C$ and $D$ respectively. Arrows in A-D represent the time stimuli were delivered to the nerve. The rectangular pulses at the beginning of sweep are time and amplitude calibration signals. Voltage calibration of $15 \mathrm{mV}$ applies to $\mathrm{A}$ and $\mathrm{B}$, and $3 \mathrm{mV}$ to $\mathrm{C}-\mathrm{F}$. Time calibration of $2 \mathrm{msec}$ applies to A, $3 \mathrm{msec}$ to $\mathrm{B}$ and 10 msec to $\mathrm{C}-\mathrm{F}$. Up is positive and down is negative in all records.

then negative wave, followed by a large negative wave. The first smaller negative waves had latencies ranging from 0.6 to $1.0 \mathrm{msec}$ and durations of about $0.5 \mathrm{msec}$ and responded to high frequency $(200-1000 \mathrm{~Hz})$ stimulation. Since the action potentials of the intrafiber units usually arise within the time period of this smaller wave, the early field potential is thought to be a reflection of the reasonably synchronous fiber component. The larger negative waves, which had longer latencies $(1.0-1.5 \mathrm{msec})$ and could not follow high frequency stimulation, are thought to be the postsynaptic component, presumably the field potentials generated by second order trigeminal neurons.

When the glass recording electrode entered the preterminal fiber, the DC level would drop about 10-60 mV. A suprathreshold stimulus delivered to the corresponding Tn usually evoked an action potential with a characteristic short rising phase and relatively long falling phase (Fig. 1A). The action potential was usually followed first by a small after-hyperpolarization and later by a prolonged depolarization which was graded and could lead to one or several action potentials. 
The amplitudes of action potentials recorded from different units varied from $10 \mathrm{mV}$ to more than $60 \mathrm{mV}$, with a spike duration of $1.0-1.5 \mathrm{msec}$. The number of spikes following the first action potential varied. Sometimes no spike could be evoked, although the stimulus intensity was increased. It can be seen in Fig. 1 B that the latency of the first spike is always constant. However, the latency of the other spikes following the first one may change. If the stimulation is subthreshold for the impaled nerve fiber (Fig. 1C), the first spike does not occur and only depolarization of the nerve fiber remains. This indicates that the depolarization following the spike in Fig. ID
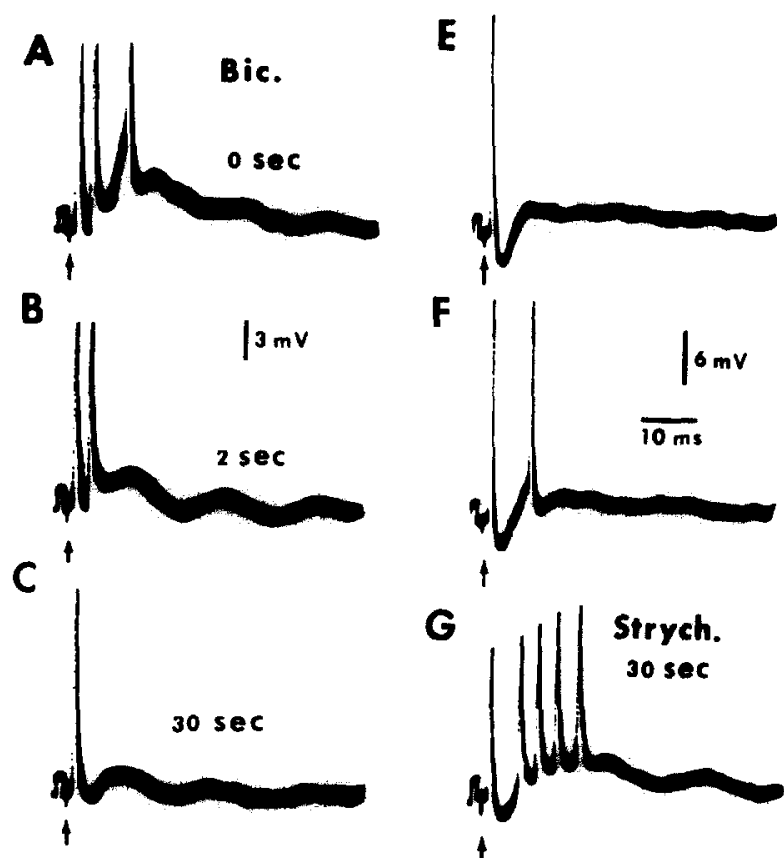

$\mathbf{F}$
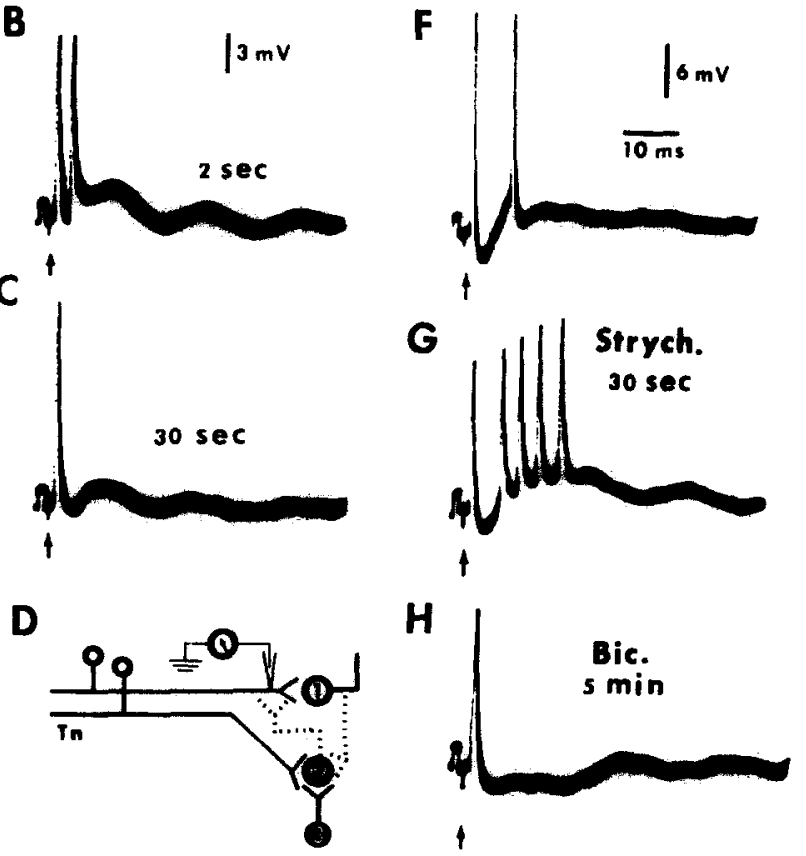

Fig. 2. Drug effect on the PAD and TDRR recorded from the central preterminal of an infraorbital nerve fiber. A-C: the effect of bicuculline (Bic) on an intrafiber unit. A: a recording taken just before Bic was injected. This serves as a control. B: $2 \mathrm{sec}$ after Bic administration was completed. C: $30 \mathrm{sec}$ after injection. The peaks of the spikes were out of the scope. Calibration signals preceding the spike(s) represent $1 \mathrm{msec}(\mathrm{A}-\mathrm{C}$ and $\mathrm{E}-\mathrm{H})$ and $1 \mathrm{mV}(\mathrm{A}-\mathrm{C})$ or $2 \mathrm{mV}(\mathrm{E}-\mathrm{H})$. Arrows represent the instant at which stimuli were delivered to infraorbital nerve fiber. $\mathbf{E}-\mathbf{H}$ : the effect of strychnine (strych.) and Bic on another fiber unit. The beginning of the sweep was out of the scope ( $E$ and $F$ ). $G: 30$ sec after strych. was injected. $\mathrm{H}: 5 \mathrm{~min}$ after the Bic was given following the strych. test. Voltage calibration of $3 \mathrm{mV}$ applies to A-C and $6 \mathrm{mV}$ to E-H. Time calibration of $10 \mathrm{msec}$ applies to all the traces. D: a summary diagram of a possible explanation of the observed phenomena. Tn, trigeminal peripheral nerve; empty circles, excitatory neurons; filled circle, inhibitory neuron; dotted lines, monosynaptic or multisynaptic connections. Up is positive and down is negative in all records. 
does not represent the intrinsic spike after-potential of the nerve fiber, and the spikes following the first one in Fig. 1B are not dependent on the first spike and may involve a neural pathway of more than one synapse.

From the latency $(0.9 \mathrm{msec})$ and conduction distance $(50 \mathrm{~mm})$ of the impaled fiber (Fig. 1), its conduction velocity can be calculated as $56 \mathrm{~m} / \mathrm{sec}$, suggesting that this fiber is a low threshold A fiber. Because the stimulus intensity used to activate the PAD in Fig. 1C was lower than that of this fiber, it is reasonable to assume that at this stimulus strength, the peripheral fibers involved in the production of the PAD of the impaled fiber are low threshold, large A fibers.

To determine what factors influence the production of the PAD, experiments were performed using bicuculline and strychnine. Bicuculline's depressive action on segmental presynaptic inhibition in spinal animals has been reported in the literature $5,18,19$. The dorsal root potential evoked by sensorimotor cortex input is enhanced by bicuculline ${ }^{3}$. While it appears that the effect of bicuculline on the dorsal root potentials of the spinal nerves depends on the pathways that subserve the above phenomena, the antagonistic effect of bicuculline on GABA at a variety of synaptic sites seems to be established $5,8,9,18-20$.

Bicuculline $(1 \mathrm{mg} / \mathrm{kg})$ was injected intravenously and recordings were made at the time of injection (Fig. 2A), $2 \mathrm{sec}$ (Fig. 2B) and $30 \mathrm{sec}$ (Fig. 2C) after the injection was completed. At time 0 , two spikes followed the first activation of the impaled nerve fiber by single pulse stimulation. The PAD was prominent. In Fig. 2B, the number of spikes was reduced and so was the amplitude of the PAD. In Fig. 2C, the second spike no longer appeared and the PAD was much reduced.

In another experiment strychnine $(0.1 \mathrm{mg} / \mathrm{kg})$ and bicuculline were used sequentially to give a clue to the nature of the transmitter liberated by nerve terminals affecting PAD production in the trigeminal nuclei. Prior to strychnine injection, the PAD was small (Fig. 2E and F) and occasionally one spike could be elicited on top of the PAD (Fig. 2F). Thirty seconds after the strychnine was administered, the PAD was much enhanced and several spikes were readily elicited (Fig. 2G). Bicuculline was then injected and the first action potential, activated by direct stimulation of the impaled nerve fiber, was unaffected. However, the PAD and later spikes declined gradually and were abolished after 5 min (Fig. 2H).

The diagram in Fig. 2D illustrates the basis for an interpretation of possible spinal trigeminal nucleus organization. The latency of the PAD (Fig. 1C) activated by other low threshold fibers is $2 \mathrm{msec}$. It takes from 0.6 to $0.9 \mathrm{msec}$ for the faster conducting fibers to carry impulses to the rostral part of the spinal nucleus. Therefore, the latency of the PAD inside the spinal nucleus is 1.1-1.4 msec. This range of values is smaller than that obtained by other investigators recording in the spinal cord ${ }^{12,17}$ or cuneate nucleus ${ }^{1}$. However, the range of values would still permit a pathway that includes 2 synapses in series, just as has been postulated for the simplest pathway for PAD production in the dorsal column nuclei ${ }^{1}$.

The diagram shows that when the stimulus intensity does not reach the threshold of the impaled nerve fiber, the PAD activation goes through neuron 2 and then either directly or multisynaptically impinges upon the terminal of the impaled nerve 
fiber. Functionally this pathway might serve as first order spatial regulation of sensory information. When the stimulus reaches threshold, the other pathway, which involves neuron 1 alone or more neurons in series, could also affect neuron 2. This pathway would serve as temporal, as well as spatial, regulation at the primary afferent. The organization is very similar to that of dorsal column nuclei studied by other investigators. GABA probably acts as a neurotransmitter in these circuits because bicuculline, the GABA antagonist, could effectively inhibit the PAD and TDRR as revealed by intracellular recordings. Neuron 2 is subject to modification by inhibitory inputs from neuron 3. That inhibitory neurons modulate the PAD pathway is shown by the increase in the PAD and TDRR after the intravenous administration of strychnine, a convulsant drug which reduces the IPSP in a variety of central neurons. The parallel phenomenon of strychnine increasing both the amplitude and duration of the negative dorsal root potential has been reported at the spinal cord level $4,14,18,24$. Many of the inhibitory neurons are probably located in the caudal part of the spinal nucleus. When a tractotomy was performed at the obex level, the excitability of primary afferent preterminals was augmented ${ }^{16}$.

We thank Drs. K. L. Casey, R. M. Bradley, C. M. Mistretta, and L. Brinkley for reviewing this paper, and C. Blaum and D. Evangelidis for technical assistance.

We acknowledge financial support from the National Institute for Dental Research Grant DE 02731-06.

1 Andersen, P., Eccles, J. C., Schmidt, R. F., And Yokota, T., Depolarization of presynaptic fibers in the cuneate nucleus, $J$. Neurophysiol., 27 (1964) 92-106.

2 Baldissera, F., Broggi, G., ANd Mancia, M., Depolarization of trigeminal afferents induced by stimulation of brain stem and peripheral nerves, Exp. Brain Res., 4 (1967) 1-17.

3 Benoist, J. M., Besson, J. M., Conseiller, C., AND LeBars, D., Action of bicuculline on presynaptic inhibition of various origins in the cat's spinal cord, Brain Research, 43 (1972) 672-676.

4 Brooks, C. MCC., AND KoIzUmI, K., Origin of the dorsal root reflex, J. Neurophysiol., 19 (1956) 61-74.

5 Curtis, D. R., Duggan, A. W., Felix, D., and Johnston, G. A. R., Bicuculline, an antagonist of GABA and synaptic inhibition in the spinal cord of the cat, Brain Research, 32 (1971) 69 -96.

6 Curtis, D. R., ANd Ryall, R. W., Pharmacological studies upon spinal presynaptic fibers, Exp. Brain Res., 1 (1966) 195-204.

7 Darian-Smith, I., Presynaptic component in the afferent inhibition observed within the trigeminal brain stem nuclei in the cat, $J$. Neurophysiol., 28 (1965) 695-709.

8 Davidoff, R. A., Gamma-aminobutyric acid antagonism and presynaptic inhibition in the frog spinal cord, Science, 175 (1972) 331-333.

9 DeGroat, W. C., Lalley, P. M., And Block, M., The effects of bicuculline and GABA on the superior cervical ganglion of the cat, Brain Research, 25 (1971) 665-668.

10 Dubner, R., AND Sessle, B. J., Presynaptic excitability changes of primary afferent and corticofugal fibers projecting to trigeminal brain stem nuclei, Exp. Neurol., 30 (1971) 223-238.

11 Dubner, R., Sessle, B. J., ANd Gobel, S., Presynaptic depolarization of corticofugal fibers participating in a feedback loop between trigeminal brain stem nuclei and sensorimotor cortex, Nature (Lond.), 223 (1969) 72-73.

12 Eccles, J, C., Kostyuk, P. G., ANd Schmidt, R. F., Pathways responsible for depolarization of primary afferent fibers, J. Physiol. (Lond.), 161 (1962) 237-257.

13 Eccles, J. C., Schmidt, R. F., ANd Willis, W. D., Depolarization of the central terminals of cutaneous afferent fibres, J. Neurophysiol., 26 (1963) 646-661. 
14 Eccles, J. C., Schmidt, R., AND Willis, W. D., Pharmacological studies on presynaptic inhibition, J. Physiol. (Lond.), 168 (1963) 500-530.

15 Franz, D. N., AND IGgo, A., Dorsal root potentials and ventral root reflexes evoked by nonmyelinated fibers, Science, 162 (1968) 1140-1142.

16 KING, R. B., Interaction of peripheral inputs within the trigeminal complex. In J. F. BosmA (Ed.), Oral Sensation and Perception, Thomas, Springfield, Ill., 1970, pp. 119-131.

17 KOKETSU, K., Intracellular potential changes of primary afferent nerve fibers in spinal cords of cats, J. Neurophysiol., 19 (1956) 375-392.

18 Levy, R. A., AND ANDErson, E. G., The effect of GABA antagonists bicuculline and picrotoxin on primary afferent terminal excitability, Brain Research, 43 (1972) 171-180.

19 Levy, R. A., AND ANDerson, E. G., Bicuculline and picrotoxin blockade of positive dorsal root potentials, Nature New Biol., 241 (1972) 156-158.

20 Levy, R. A., Repkin, A. H., AND Anderson, E. G., The effect of bicuculline on primary afferent terminal excibility, Brain Research, 32 (1971) 261-265.

21 Schmidt, R. F., Senges, J., And Zimmermann, M., Presynaptic depolarization of cutaneous mechanoreceptor afferents after mechanical skin stimulation, Exp. Brain Res., 3 (1967) 234-247.

22 Sessle, B. J., ANd Dubner, R., Presynaptic hyperpolarization of fibers projecting to trigeminal brain stem and thalamic nuclei, Brain Research, 22 (1970) 121-125.

23 Stewart, JR., D. H., Scibetta, C. J., AND KING, R. B., Presynaptic inhibition in the trigeminal relay nuclei, $J$. Neurophysiol., 30 (1967) 135-153.

24 Tebécis, A. K., AND Phillis, J. W., The use of convulsants in studying possible function of amino acids in the toad spinal cord, Comp. Biochem. Physiol., 28 (1969) 1303-1315.

25 WALL, P. D., Excitability changes in afferent fiber terminations and their relation to slow potentials, J. Physiol. (Lond.), 142 (1958) 1-21.

26 Young, R. F., AND KING, R. B., Excitability changes in trigeminal afferent fibers in response to noxious and non-noxious stimuli, J. Neurophysiol., 35 (1972) 87-95. 